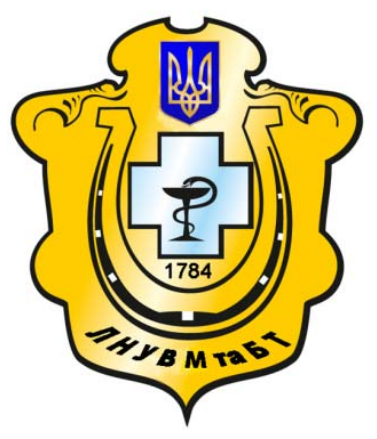

Науковий вісник Львівського національного університету ветеринарної медицини та біотехнологій імені С.3. Гжицького

Scientific Messenger of Lviv National University of Veterinary Medicine and Biotechnologies named after S.Z. Gzhytskyj

doi:10.15421/nvlvet7026

ISSN 2413-5550 print

ISSN 2518-1327 online

$\underline{\text { http://nvlvet.com.ua/ }}$

УДК 619: 616.36-091: 616.99: 636.7

\title{
Патоморфологічні зміни в печінці собак за експериментального саркоцистозу
}

\author{
В.С. Зворигіна, М.П. Прус, Б. В. Борисевич \\ zvorygina90@mail.ru \\ Національний університет біоресурсів і природокористування Украӥни, \\ вул. Героїв Оборони, 15, м. Київ, 03041, Украӥна
}

\begin{abstract}
В результаті проведених досліджень встановили основні макро- та мікроскопічні зміни в печінщі собак за експериментального саркоиистозу. Для досягнення мети було відібрано троє клінічно здорових иуценят віком 2 - 4 місяці, яких піддали зараженню иляхом згодовування протягом трьох діб фаршу з яловичих сердець, вражених саркоцистами. Тварин піддали евтаназї̈ на 7, 14 та 21 добу після зараження. Патологоанатомічний розтин проводили методом часткової евісцерації у загальноприйнятій послідовності. Для виявлення мікроскопічної будови печінки зрізи товщиною 7 - 10 мкм, отримані за допомогою санного мікротому, зафарбовували гематоксиліном Карачі та еозином. Для виявлення ліпідів на заморожуючому мікротомі виготовляли заморожені зрізи товщиною 15 - 20 мкм, які зафарбовували Суданом ІІІ. Морфометрію проводили за методикою Г.Г. Автандилова. В результаті проведених досліджень встановили: в усіх собак печінка макроскопічно мала не змінені розміри, ії краї місиями були загострені, виявлялися ділянки різних розмірів і форми сіруватого й синюшного кольору. Макроскопічні зміни в печінці собак за експериментального саркоцистозу нехарактерні. При проведенні гістологічних досліджень в печінці встановили венозний застій і тотальну тяжку зернисту дистрофію гепатоцитів. Встановлено розвиток гаметогонії і спорогонії саркоцист в клітинах печінки.
\end{abstract}

Ключові слова: собаки, саркочистоз, мікрогаметоцит, спороциста, спорозоїт, патоморфологічні зміни, макроскопічні зміни, мікроскопічні зміни, печінка, гепатоцит, ендотелій.

\section{Патоморфологические изменения в печени собак при экспериментальном саркоцистозе}

\author{
В.Е. Зворыгина, М.П. Прус, Б.В. Борисевич \\ zvorygina90@mail.ru
}

Наџиональный университет биоресурсов и природопользования Украины, ул. Героев Обороны, 15, г. Киев, 03041, Украина

В результате проведенных исследований установили основные макро-и микроскопические изменения в печени собак при экспериментальном саркоцистозе. Для достижения иели были отобраны три клинически здоровых щенка в возрасте 2 - 4 месяиа, которых подвергли заражению путем скармливания на протяжении трех суток фарша из говяжьих сердец, пораженных саркоцистами. Животных подвергли эвтаназии на 7, 14 и 21 сутки после заражения. Патологоанатомическое вскрытие проводили методом частичной эвисиеращии в общепринятой последовательности. Для выявления микроскопического строения печени срезы толщиной 7 - 10 мкм, полученные с помощью санного микротома, окрашивали гематоксилином Караии и эозином. Для выявления липидов на замораживаютем микротоме изготавливали замороженные срезы толщиной 15 - 20 мкм, которые окрашивали Суданом III. Морфометрию проводили по методике Г.Г. Автандилова. В результате проведенных исследований установили: у всех собак печень макроскопически имела неизмененные размеры, ее края местами были заостренные, выявляли участки различных размеров и формы серого и синюшного иветов. Макроскопические изменения в печени собак при экспериментальном саркочистозе нехарактерные. При проведении гистологических

\section{Citation:}

Zvorygina, V.E., Prus, M.P., Borysevich, B.V. (2016). Pathomorphological changes in the liver of dogs in case of experimental sarcocystosis. Scientific Messenger LNUVMBT named after S.Z. Gzhytskyj, 18, 3(70), 112-114. 
исследований в печени установили венозный застой и тотальную тяжелую зернистую дистрофию гепатоиитов. Установлена возможность развития гаметогонии и спорогонии саркоцист в клетках печени.

Ключевые слова: собаки, саркоцистоз, микрогаметоциты, спороциста, спорозочт, патоморфологические изменения, макроскопические изменения, микроскопические изменения, печень, гепатоциты, эндотелий.

\title{
Pathomorphological changes in the liver of dogs in case of experimental sarcocystosis
}

\author{
V.E. Zvorygina, M.P. Prus, B.V. Borysevich \\ zvorygina90@mail.ru
}

\author{
National university of life and environmental sciences of Ukraine, \\ Heroyiv Oborony Str., 11, Kyiv, 03041, Ukraine
}

\begin{abstract}
Basic macro- and microscopic changes in the liver of dogs in case of experimental sarcocystosis were determined as a result of our studies. Three clinically healthy puppy aged $2-4$ months who were subjected to infection by feeding within three days of minced beef hearts, affected by sarcocysts, were selected for the experiment. The animals were subjected to euthanasia at the 7th, 14th and 21 st day after infection. Autopsy was performed by partial evisceration in the conventional sequence. To detect microscopic structure of the liver, slices of $7-10 \mu \mathrm{m}$ thickness, obtained by the sliding microtome, were stained by hematoxylin and eosin Karazi. For detection of the lipids, frozen sections of thickness $15-20 \mu \mathrm{m}$, stained by Sudan III, were produced by using freezing microtome. Morphometry was performed due to G. Avtandylov. As a result of the research it was established that liver of all dogs macroscopically had not changed in size, its edges were sometimes sharpened, areas of different sizes and shapes of bluish and gray colors were seen. Macroscopic changes in the liver of dogs in case of experimental sarcocystosis were uncharacteristic. Conducting histology research, venous stasis and total hard granular dystrophy of hepatocytes in liver were determined. In case of experimental sarcocystosis of dogs the possibility of gametogony and sporogony of the causative agent in the liver was established.

Key words: dogs, sarcocystosis, microgametocyte, sporocyst, sporozoite, pathological changes, macroscopic changes, microscopic changes, liver, hepatocytes, endothelium.
\end{abstract}

\section{Вступ}

Саркоцисти - одноклітинні організми 3 родини Eimeriidae, вперше описані у 1843 році Мішером, які були виявлені у посмугованих м'язах хатньої миші. На сьогоднішній день відомо понад 100 видів саркоцист, проте повний цикл розвитку розшифрований тільки для деяких 3 них. Так, 3 літературних даних відомо, що саркоцисти - облігатно гетероксенні паразити, тобто їх цикл розвитку включає обов'язкову участь двох хазяїв - дефінітивного (м'ясоїдні тварини та людина) та проміжного (велика та дрібна рогата худоба, свині, коні тощо) (Fayer, 2004). У дефінітивного хазяїна збудник локалізується в тонкому відділі кишечника, де проходить статеву фазу розвитку, яка закінчується формуванням і виділенням 3 фекаліями у зовнішнє середовище інвазійних для проміжного хазяїна спорульованих ооцист $з$ двома спороцистами, що містять чотири спорозоїти. Відомо, що паразитування збудника в тонкому відділі кишечника викликає певні деструктивні зміни (Dubey and Speer, 1991). Однак, в доступних літературних джерелах інформація щодо патоморфологічних змін в організмі собак за експериментального саркоцистозу майже відсутня. Особливо це стосується печінки. Тому перед нами постала мета - встановити макро- та мікроскопічні зміни в печінці собак за експериментального саркоцистозу. Для досягнення мети були поставлені такі завдання: відтворити експериментальний ентеральний саркоцистоз у собак; провести евтаназію тварин на 7 , 14 та 21 добу після зараження; вивчити макро- та мікроскопічні зміни в печінці.

\section{Матеріал і методи досліджень}

Для вивчення мікроскопічних змін у печінці собак за експериментального саркоцистозу було відібрано троє клінічно здорових цуценят віком $2-4$ місяці. Після 14-ти денного карантинування, собаки були піддані зараженню шляхом згодовування протягом трьох діб фаршу з яловичих сердець, вражених саркоцистами. Тварин піддали евтаназії на 7, 14 та 21 добу після зараження. Патологоанатомічний розтин тварин проводили методом часткової евісцерації за загальноприйнятою схемою (Zon et al., 2009). Для гістологічних досліджень відбирали шматочки з різних ділянок печінки. Відібрані шматочки фіксували в 10\% водному нейтральному розчині формаліну та після зневоднення в етанолах зростаючої концентрації через хлороформ заливали в парафін. Зрізи товщиною 7 10 мкм одержували за допомогою санного мікротому. Для виявлення мікроскопічної будови печінки зрізи зафарбовували гематоксиліном Караці та еозином. Для виявлення ліпідів на заморожуючому мікротомі виготовляли заморожені зрізи товщиною 15 - 20 мкм, які зафарбовували Суданом III (Goral's'kyj et al., 2005). Морфометрію проводили за методикою Г.Г. Автандилова (Avtandilov, 1990).

\section{Результати та їх обговорення}

При проведенні патологоанатомічного розтину нами було встановлено, що в усіх собак печінка мала не змінені розміри, іiі краї місцями були загострені, 
виявлялися ділянки різних розмірів і форми сіруватого й синюшного кольору.

При проведенні гістологічних досліджень виразні мікроскопічні зміни також були виявлені в печінці усіх експериментально заражених собак. При цьому встановлювали розширення й переповнення кров'ю центральних вен і вен печінкових тріад (венозний застій крові). Проте найбільш виразні мікроскопічні зміни було виявлено в гепатоцитах усіх без виключення печінкових часточок, тобто мало місце дифузне ураження паренхіми цього органу.

Балочна будова печінкових часточок зберігалась лише місцями. Всі гепатоцити перебували в стані зернистої дистрофії. Частина дистрофічно змінених клітин руйнувалась. У цитоплазмі частини дистрофічно змінених клітин виявлялись напівпрозорі та прозорі вакуолі відносно невеликих розмірів у кількості від однієї до семи. Оскільки характерне для жирової дистрофії накопичення ліпідів при зафарбовуванні заморожених зрізів печінки Суданом III в цитоплазмі гепатоцитів виявлено не було, на нашу думку такі зміни свідчили про початкову стадію переходу зернистої дистрофії в гідропічну, тобто про прогресування дистрофічних змін гепатоцитів.

Вакуолі в цитоплазмі гепатоцитів у багатьох випадках були оточені дещо базофільними стінками. Такі зміни цитоплазми свідчили про значні порушення як фізико-хімічного стану цитозолю, так і фізикохімічного стану мембранних компонентів цитоплазми.

В печінці собаки № 2, крім вище описаних змін, нами було встановлено розмноження збудника хвороби. У внутрішньочасточкових капілярах багатьох печінкових часточок виявлялися мікрогаметоцити та спороцисти зі спорозоїтами. Інші стадії циклу розмноження паразита нами зареєстровані не були.

Кожен мікрогаметоцит містив багато ядер різних розмірів, округлої, овальної й витягнутої форми. Ці ядра інтенсивно зафарбовувались гематоксиліном Караці, а інший уміст мікрогаметоцита досить рівномірно зафарбовувався еозином. Всі мікрогаметоцити мали округлу форму, діаметр $25 \pm 2$ мкм. Ядра розташовувались у мікрогаметоциті нерівномірно. Їх розміри складали $4 \pm 3$ мкм.

Мікроскопічна будова й розміри спороцист у печінці не відрізнялися від таких у тонкій кишці. Кожна спороциста містила 4 спорозоїти. Спорозоїти інтенси- вно зафарбовувались гематоксиліном Караці, а інший уміст спороцисти досить рівномірно зафарбовувався еозином. Спороциста мала округлу форму, діаметр $26 \pm 3$ мкм. Спорозоїти досить рівномірно розташовувались у спороцисті. Вони також мали округлу форму й діаметр $6 \pm 1$ мкм.

Непрямим свідченням розмноження збудника хвороби в печінці, на нашу думку, також було те, що ендотелій усіх кровоносних судин (судини усіх тріад (артерії й вени), центральні вени всіх печінкових часточок і всіх внутрішньочасточкових капілярів усіх печінкових часточок) був повністю зруйнований. На його місці залишались клітинний детрит і поодинокі напівзруйновані ендотеліоцити.

\section{Висновки}

Макроскопічні зміни в печінці собак за експериментального саркоцистозу нехарактерні. При проведенні гістологічних досліджень в печінці встановили венозний застій і тотальну тяжку зернисту дистрофію гепатоцитів. Встановлено розвиток гаметогонії і спорогонії саркоцист в клітинах печінки.

У подальшому необхідно встановити мікроскопічні зміни в інших органах собак за експериментального саркоцистозу.

\section{Бібліографічні посилання}

Avtandilov, G.G. (1990). Medicinskaja morfometrija. Rukovodstvo. M.: Medicina (in Russian).

Goral's'kyj, L.P., Homych, V.T., Konons'kyj, O.I. (2005). Osnovy gistologichnoi' tehniky i morfofunkcional'ni metody doslidzhennja u normi ta pry patologii'. Zhytomyr: Polissja (in Ukrainian).

Zon, G.A., Skrypka, M.V., Ivanivs'ka, L.B. (2009). Patologoanatomichnyj roztyn tvaryn. Donec'k. (in Ukrainian).

Dubey, J.P., Speer C.A. (1991). Sarcocystis canis sp. (Apicomplexa: Sarcocystidae), the etiologic agent of generalized coccidiosis in dogs. J. Parasitol. 77, 522527

Fayer, R. (2004). Sarcocystis spp. in Human Infections. Clin. Microbiol. Rev. 17, 4, 894-902

Стаття надійшла до редакиії 1.09.2016 